\title{
Expanding Understanding of Emergent Literacy: Empirical Support for a New Framework
}

\author{
Karen A. Erickson and Deborah Hatton
}

\begin{abstract}
Emergent literacy in young children with visual impairments is examined using a conceptual framework proposed by Sénéchal, LeFevre, SmithChant, and Colton (2001). The utility of this framework for young children with visual impairments is illustrated using data from a field study of preschool classes for children with visual impairments.
\end{abstract}

Relatively little is known about the development of language and literacy in children with visual impairments (that is, those who are blind or have low vision). The research that has been conducted suggests that these children are at risk of experiencing delays in the development of language and literacy (Bigelow, 1987; Fraiberg, 1977; Preisler, 1995; Urwin, 1984). From early ages, children who are visually impaired show delays or differences in babbling (Fraiberg, 1977); speaking in one- and two-word combinations (McConachie, 1990; McConachie \& Moore, 1994); and in using language (Anderson, Dunlea, \& Kekelis, 1984; Bigelow, 1987; Sapp, 2001; Urwin, 1984). Furthermore, differences have been found between children with visual

Preparation of this article was made possible, in part, by Grant H324D020047 from the U.S. Department of Education. However, the contents do not necessarily represent the policy of the Department of Education, and endorsement by the federal government should not be assumed. The authors thank Dana Lee Fox and Jeanne L. Murphy for their contributions to the project. impairments and other children with respect to the frequency of reading storybooks and engaging in other literacy learning experiences (Stratton \& Wright, 1991), as well as general opportunities to explore the world (Wormsley \& D'Andrea, 1997). It appears that limited incidental learning through pictures, television, print in the environment, or events that occur silently in learning environments (Koenig \& Farrenkopf, 1997) influences the language and literacy learning of children who are visually impaired.

As interest in understanding emergent literacy for children with visual impairments continues to increase, it seems important to develop or adopt a conceptual framework to guide both research and practice. Starting with a well-defined conceptual model will provide researchers and practitioners with a common language and conceptual understanding from which they can develop a model that will best fit the characteristics of literacy and of language learners who are visually impaired. Whether the field of visual impairment and blindness eventually chooses to 
adopt a conceptual framework that is developed to explain the development of literacy for sighted children or to create one of its own will depend largely on the fit between these models and the growing evidence base. In this article, we describe a conceptual framework of emergent literacy that was developed for sighted children and provide initial evidence of its applicability to children who are visually impaired using data that were collected in a field study that investigated literacy practices for young children with visual impairments in preschool settings.

\section{Emergent literacy}

The conceptual framework described here was selected because it encompasses a holistic understanding of emergent and early literacy that incorporates all aspects of written and oral language (Anderson, Hiebert, Scott, \& Wilkinson, 1985; Clay, 1966, 1979; Teale \& Sulzby, 1986). Furthermore, it encompasses the extant definitions of emergent literacy for young children who are visually impaired (D'Andrea \& Farrenkopf, 2000; Stratton \& Wright, 1991) and the specific practices for promoting emergent literacy that have been recommended in the literature (Swenson, 1999; Wormsley, 1997). The conceptual framework was also selected because it provides a description of the constructs underlying emergent and early literacy, rather than of the behavioral indicators or components of emergent literacy that are described in other models (see Mason \& Stewart, 1990; Whitehurst \& Lonigan, 1998). This distinction is important, given the likelihood that there will be substantial behavioral differences in the demonstration of an increasing knowledge of literacy by young sighted children and those with visual impairments, particularly those who will read braille.

The conceptual framework (see Figure 1) is based on the work of Sénéchal, LeFevre, Smith-Chant, and Colton (2001), who suggested that emergent literacy is comprised of at least three important constructs: oral language, metalinguistic skills, and literacy knowledge (conceptual and procedural). In explaining the framework, we offer no distinction between emergent literacy as an initial phase and early literacy as a transitional phase (see Chall, 1983; Holdaway, 1979). Rather, we describe emergent and early literacy as a continuum of all the behaviors, skills, processes, and concepts about written and oral language that precede and develop into conventional literacy skills (Sulzby, Branz, \& Buhle, 1993; Teale \& Sulzby, 1986). Furthermore, we do not describe the behavioral indicators or components of emergent literacy (as do Mason \& Stewart, 1990, or Whitehurst \& Lonigan, 1998), but define the constructs that constitute early and emergent literacy.

The interrelationships among the constructs that make up early and emergent literacy have been well documented (Bowey, 1994; Bowey \& Patel, 1988; Dickinson, McCabe, Anastasopoulos, Peisner-Feinberg, \& Poe, 2003; Dickinson \& Snow, 1987; Scarborough, 2001; Tabors, Roach, \& Snow, 2001), but the interrelationships do not preclude the observation, measurement, development, and description of the three as separate constructs. At the most basic level, two of the three constructs are separated on the basis of arguments that oral language is "biologically primary" and develops for most children in the absence of any formal instruction or particular opportunities, whereas print or literacy skills are 


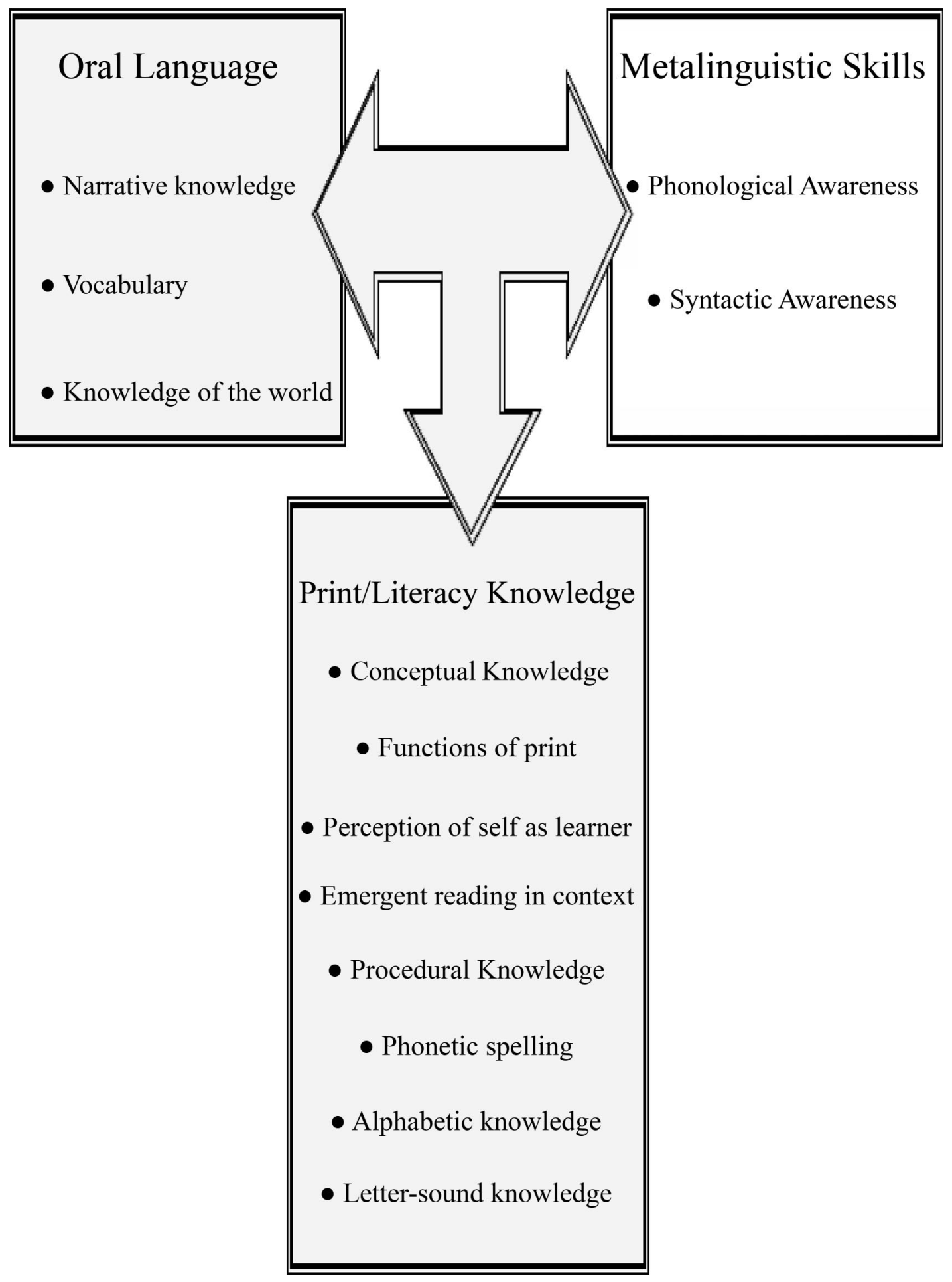

Figure 1. A proposed model of the constructs of emergent and early literacy (adapted from Sénéchal, LeFevre, Smith-Chant, Colton, 2001). 
"biologically secondary" and require specific exposure to experiences or instruction to develop (Geary, 1995; Jordan, Snow, \& Porche, 2000; Sénéchal et al., 2001; Snow, 1983). From an empirical perspective, the existence of the three separate constructs has been confirmed by statistical models that demonstrate that a separation of the three constructs (in contrast to one or two) best explains children's developing literacy skills (Lonigan, Burgess, \& Anthony, 2000; Sénéchal et al., 2001; Whitehurst et al., 1994). Furthermore, oral language abilities in early childhood explain the variance in later reading achievement that is unique from metalinguistic skills or literacy knowledge as separate constructs (Biemiller, 1999; Cunningham \& Stanovich, 1997; Dickinson \& Tabors, 2001; Sénéchal \& LeFevre, 2002). Likewise, metalinguistic abilities are individually strong predictors of later reading achievement (Scarborough, 1998; Sénéchal \& LeFevre, 2002; Wagner et al., 1997).

Recent research with sighted children has suggested that the processes, skills, and knowledge that fall under the construct of oral language are the best composite predictors of later success in the acquisition of literacy (Catts, Fey, Tomblin, \& Zhang, 2002; NICHD Early Child Care Research Network, 2005). Oral language has long been accepted as a critical construct in emergent and early literacy (Clay, 1966; Holdaway, 1979; Teale \& Sulzby, 1986; Whitehurst \& Lonigan, 1998). It is used here to specify those oral language processes, skills, and understandings that exist in the linguistic domain whether or not the interaction involves literacy. At a minimum, they include receptive and expressive vocabu- lary, comprehension beyond the word level, semantic knowledge, conceptual knowledge, and narrative knowledge.

Metalinguistic skills have been the focus of a great deal of attention in the literature and in practice over the past decade (Cronin \& Carver, 1998; Foorman \& Torgesen, 2001; Speece, Roth, Cooper, \& de la Paz, 1997; Vellutino \& Scanlon, 2001; Wagner et al., 1997), including two investigations with young children with visual impairments (Barlow-Brown \& Connelly, 2002; Gillon \& Young, 2002). The term metalinguistic denotes an awareness of language that is secure enough for individuals to talk about it (Herriman, 1991). The construct label metalinguistic skill is used here to define both phonological awareness (a variety of skills related to awareness of the sound structure of oral language, including phonemic awareness as a specific subset of phonological skills) and syntactic knowledge (an understanding of the way in which sentences are constructed). The relationship between the development of metalinguistic skills and later reading performance is strong and has been well documented for sighted children (for a complete review, see Dickinson et al., 2003; Schatschneider, Fletcher, Francis, Carlson, \& Foorman, 2004) and supported by research with children with visual impairments (BarlowBrown \& Connelly, 2002; Dodd \& Conn, 2000; Gillon \& Young, 2002).

The construct literacy knowledge is used here to reflect all the processes, skills, and understandings in emergent or early literacy that relate directly to written language. Literacy knowledge includes conceptual knowledge, such as perception of oneself as a reader or writer, knowledge of the functions of print, and knowledge of the act of reading. It also includes 
procedural knowledge, such as concepts about print, knowledge of the alphabet, letter-sound knowledge, and phonetic spelling. The distinguishing feature of all these processes, skills, and understanding is that they develop only when print or its equivalent is present in the environment. Unlike oral language and metalinguistic knowledge, which are often viewed as biologically primary, the development of literacy knowledge is viewed as biologically secondary and requires activities and experiences that directly involve print or its equivalent (Geary, 1995; Sénéchal et al., 2001). To support the application of this conceptual framework to young children with visual impairments, we use data from an investigation of preschool classrooms serving young children who are visually impaired to demonstrate our assertion that it can serve as a framework for both emergent literacy intervention and research with young children with visual impairments.

\section{The study}

The specific examples that we use in the following description of the constructs underlying Sénéchal et al.'s (2001) model came from a formal field study; however, for the purposes of this discussion, we culled the data for specific "best examples," rather than analyzed them through some form of grounded theory. In other words, the proposed conceptual framework did not result from data; the data are used to support the applicability of the model.

The participants in the study were three preschool teachers of children with visual impairments-Wendy, Pat, and Nancy (pseudonyms) — who work exclusively with young visually impaired children at specialized agencies that provide services to young children with visual impairments in three regions of the United States. Wendy, Pat, and Nancy have all been teaching young children who are visually impaired for more than 20 years. Wendy and Nancy each had the same group of five to seven children (aged 4-6) in their respective preschool and kindergarten classrooms five days each week. The nine children, including two with multiple disabilities, in Pat's classroom attended preschool two or three mornings a week.

The data reported here came from field notes, interviews, and reviews of documents that were used to collect data for the study. Written informed consent was obtained from the teachers and parents of children in the three classrooms using procedures approved by the institutional review board of the university where we are employed. Data were collected in the schools by research assistants and transmitted to the authors who reviewed the data for completeness, and summarized, and analyzed it. A total of eight observations were conducted in each classroom, with no more than one observation completed in a single week. The three preschool classrooms were observed for a combined total of 24.5 hours, with the average length of each observation being 61.5 minutes. In addition, the teachers were interviewed formally at the beginning of the study and informally during and after observations. Reviews of documents included reviews of books used by the teachers during their sessions, lesson plans, and samples of the students' work.

In the sections that follow, examples are drawn from the data and discussed with reference to the constructs of early and emergent literacy that were described earlier: oral language, metalinguistic awareness, and literacy knowledge. Each 
section of the findings begins with an overview of the literature relating the construct to children with visual impairments, followed by specific examples from the data that relate to the construct.

\section{Oral language}

\section{Overview}

McComiskey (1996) included oral language in her description of braille readiness skills as "listening and attention" and "concept" knowledge. Concerns about the development of oral language by children who are visually impaired, including listening, attention, and concept development, have been documented for the past decade (Stratton, 1996). Differences are noted early in that infants with visual impairments appear to babble less than do sighted infants (Fraiberg, 1977). The differences continue into early childhood, since toddlers with visual impairments are often delayed in the use of one- and two-word combinations (McConachie, 1990; McConachie \& Moore, 1994), and slightly older children with visual impairments exhibit differences and delays in their overall use of language, such as prolonged periods of echolalia, the atypical use of pronouns, and the extensive use of questions (Anderson et al., 1984; Bigelow, 1987; Sapp \& Hatton, 2005b; Urwin, 1984).

There are many possible explanations for the differences and delays that are noted in the development of oral language by young children who are visually impaired. It is clear that these children often have fewer opportunities to explore the world than do sighted children (Warren \& Hatton, 2003). The development of oral language may also be influenced by the children's inability to perceive nonverbal communication (through eye contact, fa- cial expressions, and gestures) from caregivers (Preisler, 1995) and their lesser use or nonuse of facial expressions and eye contact (Fraiberg, 1977; Rogers \& Puchalski, 1984). Whatever the case, the literature has consistently revealed potential delays and differences in the development of oral language by young children with visual impairments.

The literature on young children with visual impairments offers some information on the ways in which interactions with children can have a positive influence on the children's language learning. For example, providing rich descriptions and feedback to children as they explore their environment and engaging in literacy activities can have a positive effect on oral language outcomes (Conti-Ramsden \& Perez-Pereira, 1999; Sapp \& Hatton, 2005b; Wormsley \& D'Andrea, 1997). It has also been suggested that parents, teachers, and practitioners can improve language outcomes by modeling more descriptive language in their interactions (Kekelis \& Andersen, 1984; Sapp, Murphy, \& Hatton, 2005; Warren \& Hatton, 2003), and modeling language in age-appropriate ways during storybook interactions (Hatton \& Sapp, 2005; Stratton, 1996).

\section{Findings}

The three teachers demonstrated their understanding of the importance of language through their words and actions. There were numerous instances in which they supported the development of the children's vocabulary by offering simple labels of the objects that the children encountered during the day. Whether handing out props for use during storybook reading, sharing food for a snack, or passing out materials for an activity, the 
teachers consistently labeled the objects that the children touched. In some instances, the teachers were observed providing substantial information beyond one- and two-word labels for items. For example, during one observation, Wendy's class was preparing for a Japanese tea party. Wendy began with a label for the Japanese fan and then explained that people in Japan use fans to keep cool, to dance with, and to use as decorations. The data collector wrote:

She passed around two different fans for the children to inspect visually and tactilely as she explained that one has beautiful flowers painted on it and the other folds up. While the children took turns fanning one another, they pointed out things to one another like the butterfly that appeared on one. Wendy then extended the observation and pointed out the writing on one of the fans. She explained that the writing is Japanese and probably says something like, "Have a great day" or "Good luck."

In this example, the teacher not only modeled rich, descriptive language that promoted concept development, vocabulary, and oral language, but promoted an awareness of the function of print when she noted the writing on the fans.

Another example of this kind of language expansion was observed in response to a child's interaction with some plastic spiders. The class had been singing the "Eensy Weensy Spider." During the observation, Pat was working with one child as she made a tactile picture representing the spider going up the waterspout. The child had a plastic spider to tape down on the page. While the child worked, Pat explained, "I have a teeny-teeny tiny eensy spider. I have a very little plastic spider. ... You want to know what kind of spider it is? Plastic. It's a fake spider. You probably wouldn't want to hold a real spider." While it could be argued that there is more to be gained conceptually from using a real spider for an activity such as this, Pat was precise in distinguishing the plastic spider from a real spider and used the type of redundancy in teaching vocabulary that has been identified as one of the indirect means of teaching vocabulary that is supported by research (National Reading Panel, 1998).

The teachers also built oral language in the context of storybook reading. The three often guided children through acting out the story, using props and actions as a way to support comprehension. When asked about the format of her storybook reading interactions, Pat explained:

We work on a story for about a month; the children are here two to three times a week. The difference between just hearing the story the first time and what they end up doing at the end of the month is pretty remarkable. We have adapted a process to work on just listening [comprehension] at first; then we add a lot of characterization to the adults' parts in the story....We're really looking at language at that time, a lot of nuances of sound and sound production if the children aren't speaking yet. And then we gradually add in the tactile component as much as we can, using the real concrete objects that are part of the story. We get into directed role-playing, so lots of movement is involved and to connect meanings to the actions. We let them 
work into their own role-playing with each other, and this is the fun part because this is when the stories always change and go off on tangents, and it's a delight to see what the kids do with that.

Throughout the 24.5 hours of observation, the teachers spent a considerable amount of time engaged in activities and interactions that were designed to support the development of oral language. Many of their interactions reflected the few suggestions in the literature of ways to enhance the development of oral language by young children with visual impairments, yet few of their interactions beyond repeated readings of a storybook involved print or its equivalent. All three teachers consistently used real-life objects and experiences to promote the development of vocabulary and concepts, thereby promoting oral language. For children who did not initiate language, the teachers used chants and music to encourage oral expression. If the field of visual impairment and blindness adopts the proposed conceptual framework of the development emergent literacy, future research and practice must focus more explicitly on oral language as it relates to literacy. As a field, we must increase the breadth of our understanding of the development of language in young children with visual impairments, as well as our understanding of interventions that serve to support the children's development of oral language. The literature and current investigation demonstrate that oral language has been acknowledged as an important issue in the lives of young children with visual impairments. The proposed framework should focus attention on this area.

\section{Metalinguistic KNOWLedge}

\section{Overview}

Metalinguistic knowledge, particularly phonological awareness, has been the source of several investigations involving older children with visual impairments. In one study, elementary school-aged children who were blind demonstrated better-than-expected phonological awareness skills, given their reading level, and another group of 7- to 12-year-olds who read uncontracted braille demonstrated phonological awareness skills that were commensurate with those of same-aged sighted readers (Dodd \& Conn, 2000). These findings were replicated in a larger study of children with visual impairments (Gillon \& Young, 2002). In another study that examined the phonological awareness of young children who were visually impaired, the relationship between knowledge of the alphabet and phonological awareness was found to be the same for the groups of children with and without visual impairments (Barlow-Brown \& Connelly, 2002).

A comprehensive review of the literature revealed no report of the metalinguistic skills of preschool-aged children with visual impairments. Descriptions of braille readiness skills do not include indicators of metalinguistic development (McComiskey, 1996). However, a current study involving 4- and 5-year-old children who are visually impaired (Hatton \& Erickson, 2006) has already produced findings that suggest that the recognition of letters in print or braille is not a prerequisite for the development of phonological awareness. Several preschoolaged braille readers were not able to identify a single letter presented in braille, but they achieved at least minimal success with segmenting syllables, isolating the initial 
sound in spoken words, and identifying nonrhyming words from a set of four. Although we may not be able to draw any generalizable conclusions about the development of metalinguistic skills in children who are visually impaired from these preliminary results, they do provide evidence that young children with visual impairments can and do develop phonological awareness, even in the absence of a knowledge of the alphabet.

\section{Findings}

The classroom observations again reflect the literature in that not a single instance of direct phonological-awareness intervention was recorded during the 24 observations in the three classrooms. The teachers indirectly supported the development of phonological awareness, however, by reading storybooks, singing songs, and repeating chants that contained rhymes. One example of indirect instruction in phonological awareness was observed in Nancy's class. Two of the children in her class were in a room that was designed to support orientation, mobility, and the development of gross motor skills. One boy was rocking in a boat humming along to a $\mathrm{CD}$ playing the song "Michael, Row the Boat Ashore." When the lyrics "Sister, help to trim the sail" were sung, the boy said, "Ssssssssssssssssssail, sail." Nancy replied, "Sister, sail, shore." As the song continued to play, she said, "Soul, sail, shore." While the "sh" sound at the beginning of the word shore did not precisely match the "s" sound at the beginning of the words soul and sail, the modeling of the alliteration with soul and sail is one means of indirectly supporting the development of phonological awareness in children.
Given the findings of research on the interrelationship among knowledge of the alphabet, vocabulary, and phonological awareness (Sénéchal \& LeFevre, 2002), the teachers were supporting children's eventual development of phonological awareness through the many braille- and alphabet-awareness and vocabulary experiences they offered their young students. For example, one teacher was observed helping a student locate the braille name tag in his cubby using the hand-underhand technique to help him move his fingers across the braille and saying each letter one at a time before telling him, "That spells [your name]."

Another teacher used alphabet braille boxes for each letter of the alphabet as a free-choice activity for children. Each printand braille-labeled box contained items that began with the particular letter on that box. As the child explored and named the objects in the box, the teacher sounded out the beginning sound, asked the child about beginning sounds, and provided rich descriptions of each object and its function. This activity promoted phonological awareness, alphabetic awareness, and the development of concepts and vocabulary, as well as of oral language.

Nancy used a child's homemade book of favorite things to teach knowledge of the alphabet. For example, during one observation, she was reading the homemade alphabet book with a boy. The observer wrote the following:

Nancy began, "This is [the boy's name] book of favorite things" while she turned the page. The boy immediately identified the foil lid from a yogurt container and said, "Yogurt." Nancy repeated "yogurt" and contin- 
ued, "And [the boy] really likes to drink his ?" The boy responded, "Milk," and Nancy continued, "Can you find the ' $\mathrm{m}$ ' in milk?" As the boy touched the letter, she said, "'M' says ...," and the boy replied, "Mmmm."

Metalinguistic knowledge involves the development of phonological awareness and syntactic awareness in young children. While there was some evidence that the teachers were supporting the eventual development of phonological awareness through instruction focused on awareness of the alphabet and the development of vocabulary, there were few observations of planned direct or indirect efforts to support syntactic development. One of the three teachers allowed the children to dictate experience stories, letters, and notes, thereby promoting syntactic awareness as well as awareness of the functions of print. Certainly, the teachers provided models of appropriate syntax in their own language, but they were not observed expanding or rephrasing the children's own utterances to model syntax that was slightly more sophisticated than what the children produced independently. They were also not observed engaging in shared writing lessons or other activities that would specifically promote the development of syntactic knowledge.

It is likely that the lack of research-based information on metalinguistic knowledge in young children who are visually impaired explains the lack of attention that was paid to this area during our observations of literacy instruction in preschool classrooms. However, if the proposed conceptual framework is used to guide efforts to understand emergent literacy for young children with visual impairments, research and intervention must be focused more specifically on metalinguistic knowledge.

\section{Conceptual AND PROCEDURal LITERACY KNOWLEDGE}

\section{Overview}

McComiskey (1996) included literacy knowledge in her description of braille readiness skills as "tactile," "fine motor," and "book and story" knowledge. These areas encompass many of the perceptions, skills, and understandings that are believed to be important for any child's development of conceptual and procedural literacy knowledge; miss others; and include some that do not have to be considered for children who will read and write in conventional print. For example, training in tactile perception clearly represents procedural literacy knowledge that is not a part of early and emergent literacy discussions for sighted children. Although there are many approaches to promoting efficient tactile perception, the suggestions provided by Lamb (1996) seem most consistent with the proposed conceptual framework. As Lamb noted,

Reading is essentially a language task, so it is within this context that teachers need to investigate strategies and resources for fostering early braille skills. Therefore, early braille reading activities must be language based, and associated with meaningful text. To be relevant for the reading process, training in tactile perception must be concerned with language, must be meaningful to the child, and should take into account the special skills required for reading by touch. (p. 186) 
Children develop literacy knowledge through independent explorations and adult-supported interactions with print or braille materials. Unfortunately, the literature suggests that young children with visual impairments have fewer opportunities in these areas than do those who are sighted (Craig, 1996). For example, children who will be braille readers have significantly fewer opportunities for incidental interactions with braille and fewer direct experiences in learning the braille alphabet than do children who are sighted with print and the print alphabet. (Craig, 1996; Rex, Koenig, Wormsley, \& Baker, 1995). The development of literacy knowledge in young children who are visually impaired is also complicated by the fact that it is often difficult to determine which learning medium (print, braille, or both print and braille) is appropriate for young children and how children's needs may change over time. To ensure that children with visual impairments have adequate opportunities to develop literacy knowledge, early interactions with print should include braille for any child who may require braille at some later point. Because there is a significant correlation between the age at which braille is introduced and later braille reading speed, braille should be introduced as early as possible (Legge, Madison, \& Mansfield, 1999).

\section{Findings}

The development of procedural literacy knowledge in the form of tactile perception, fine motor skills, and the mechanics of using a braillewriter played a prominent role in the classrooms we observed. Pat, in particular, emphasized the development of these skills. In her interview, she said, "I suspect kids are getting fine motor skills in every activity that they do." When probed further, Pat identified specific activities that were completed every week for the purpose of developing motor and tactile perception skills that would support the literacy skills that "will come" later. For example, a regularly observed activity involved selecting a penny bank from an elaborate classroom collection, lining up and counting out 10 pennies, and depositing the pennies in the bank one at a time. When asked in an informal interview why the penny banks were an important preliteracy activity, Pat replied:

It's a fun activity that incorporates fine motor skills-searching on the tray [for the pennies], finding and manipulating individual pennies from top to bottom or left to right, holding the pennies in a pincer grasp with the index finger and thumb, and remembering which three things are needed to do [the activity with] pennies (a tray, pennies, and a bank of the child's choice).

We also observed several lessons in two of the three classrooms on the use of braillewriters and on the promotion of awareness of the alphabet that were clearly intended to build procedural literacy knowledge. In one setting, the children practiced the appropriate finger placement and typed individual letters while singing a song (such as "A, A, What do you say?"). In another, Pat emphasized braille skills in her interactions during each observation. For example, during the morning group, the children found their name cards and hung them on an attendance chart. Four of the children had their names in uncontracted braille on their name cards. When one student had difficulty finding his card, Pat provided hand-over-finger support 
to help him find, "that good feeling of braille; it starts here."

The children seemed engaged during the braillewriter activities, even though they seemed focused on the mechanics of braille writing, rather than on the use of the braillewriter to produce functional communication. The third teacher had a writing center in her classroom that was always available for students to write notes and letters using a braillewriter; a stylus; and a variety of markers, crayons, and adaptive writing materials. Although this teacher also provided direct braille instruction, she seemed to be focused mainly on the function, rather than the mechanics, of braille.

All three teachers consistently provided the children with access to both print and braille as they directly and indirectly supported children in developing an awareness of the alphabet. For example, in each classroom, name cards were used to label cubbies, clipboards, and seats and to indicate choices of a variety of activities. The specific format of these name cards varied slightly from room to room, with one teacher's decision to include a unique tactile symbol for each child, but all the cards included the children's names in print and braille. The teachers regularly spelled out the names on the cards as they encouraged the children to read the print and braille.

All three teachers provided accessible books in print, braille, and print and braille, and read storybooks using vocal and sound effects to keep the children engaged. Two of the three teachers provided opportunities for the children to act out the stories, and one provided opportunities for the children to dictate or write or scribble about their experiences, thereby providing the children with conceptual literacy knowledge.

Compared to oral language and metalinguistic development, literacy knowledge received a great deal of attention in the classrooms we observed. This finding is not surprising, given that literacy knowledge is the part of the conceptual framework that is considered to be biologically secondary. In other words, it is not surprising that teachers would emphasize the skills that children are least likely to develop in the absence of intentional intervention.

\section{Conclusion}

During the past 10 years, the collective understanding of emergent and early literacy has grown dramatically, including knowledge of literacy for children, in general, and for children with visual impairments, in particular. If the field of visual impairment and blindness is going to build this knowledge base in a systematic and meaningful manner, the field needs a conceptual framework that best represents the constructs that serve as the basis of our growing understanding. Both empirical data and the literature suggest that the framework that was proposed by Sénéchal et al. (2001) provides a reasonable place to start.

To promote the three components of emergent literacy proposed by Sénéchal et al. (2001) in young children with visual impairments, we recommend the strategies described in Box 1. Many of these strategies were used in the three classrooms that we observed in our field study of preschool and kindergarten teachers of children with visual impairments, and others were adapted from Sapp and Hatton (2005a). 


\section{Facilitating the three components of emergent literacy: oral language, print and braille concepts, and metalinguistic awareness}

Promoting oral language in young

children with visual impairments

- Encourage children to initiate communicative exchanges and follow the children's lead

- Expand the children's language by adding meaningful descriptive information

- Encourage children to interact with each other in social learning activities

- Encourage children to tell stories to learn more about narrative structure

- Provide functional meaningful experiences to promote vocabulary and concept development

- Encourage families to engage their children in meaningful reciprocal conversations

- Encourage families to read storybooks to their children in an interactive manner

- Use music to encourage children who do not talk much to use oral language

- Use evidence-based practices to promote communication and language (Sapp et al., 2005)

\section{Promoting metalinguistic awareness} (phonological and syntactical awareness)

- Play rhyming games that encourage attention to the end sounds of words

- Encourage awareness of letters and sounds in words that are used throughout the day

- When introducing letters of the alphabet, model the sounds that the letters make and ask the children to model the sounds, too

- Use chants, rhymes, and songs related to the daily routine to encourage awareness of the sounds of words
- Promote developmentally appropriate awareness of the sounds that letters and phonemes make through planned activities and instruction

- Provide developmentally appropriate opportunities for children to write or scribble to promote invented spelling and to sound out words

- Encourage families to provide opportunities for their children to use invented spelling in developmentally appropriate activities

\section{Promoting print and braille literacy knowledge}

- Provide a variety of accessible books

- Allow children to choose the book they would like to read

- Encourage pretend reading and writing during pretend play (at an office, restaurant, and school)

- Involve children in routine reading and writing throughout the day

- Use hand-under-hand prompts to facilitate understanding of braille reading and writing

- Provide adaptive materials and opportunities for print and braille scribbling and writing

- Use functional activities to promote understanding of the function of print and braille

- Encourage parents to teach their children how to write and spell during developmentally appropriate activities at home

- Use evidence-based practices to promote print and braille literacy knowledge (Hatton \& Sapp, 2005) 


\section{References}

Anderson, E. S., Dunlea, A., \& Kekelis, L. S. (1984). Blind children's language: Resolving some differences. Journal of Child Language, 11, 645-664.

Anderson, R. C., Hiebert, E. F., Scott, J. A., \& Wilkinson, I. A. G. (1985). Becoming a nation of readers. Washington, DC: Center for the Study of Reading, National Institute of Education.

Barlow-Brown, F., \& Connelly, V. (2002). The role of letter knowledge and phonological awareness in young braille readers. Journal of Research in Reading, 25, 259270.

Bigelow, A. (1987). Early words of blind children. Journal of Child Language, 14, 47-56.

Biemiller, A. (1999). Language and reading success. Cambridge, MA: Brookline Books.

Bowey, J. A. (1994). Phonological sensitivity in novice readers and nonreaders. Journal of Experimental Child Psychology, 58, 134-159.

Bowey, J. A., \& Patel, R. K. (1988). Metalinguistic ability and early reading achievement. Applied Psycholinguistics, 9, 367384.

Catts, H. W., Fey, M. E., Tomblin, J. B., \& Zhang, X. (2002). A longitudinal investigation of reading outcomes in children with language impairments. Journal of Speech, Language, and Hearing Research, 45, 1142-1157.

Chall, J. S., (1983). Stages of reading development. New York: McGraw-Hill.

Clay, M. M. (1966). Emergent reading behavior. Unpublished doctoral dissertation. University of Auckland, Auckland, New Zealand.

Clay, M. M. (1979). The early detection of reading difficulties. Auckland, New Zealand, Heinemann.

Conti-Ramsden, G., \& Perez-Pereira, M. (1999). Conversational interactions between mothers and their infants who are congenitally blind, have low vision, or are sighted. Journal of Visual Impairment \& Blindness, 93, 691-703.

Craig, C. J. (1996). Family support of the emergent literacy of children with visual impairments. Journal of Visual Impairment \& Blindness, 90, 194-200.

Cronin, V., \& Carver, P. (1998). Phonological sensitivity, rapid naming, and beginning reading. Applied Psycholinguistics, 19, 447-462.

Cunningham, A. E., \& Stanovich, K. E. (1997). Early reading acquisition and its relation to reading experience 10 years later. Developmental Psychology, 33, 934945.

D’Andrea, F. M., \& Farrenkopf, C. (2000). Introduction: Paths to literacy. In F. M. D'Andrea \& C. Farrenkopf (Eds.), Looking to learn: Promoting literacy for students with low vision (pp. 1-9). New York: AFB Press.

Dickinson, D. K., McCabe, A., Anastasopoulos, L., Peisner-Feinberg, E. S., \& Poe, M. D. (2003). The comprehensive language approach to early literacy: The interrelationships among vocabulary, phonological sensitivity, and print knowledge among preschool-aged children. Journal of Educational Psychology, 95, 465-481.

Dickinson, D. K., \& Snow, C. E. (1987). Interrelationships among prereading and oral language skills in kindergarteners from two social classes. Early Childhood Research Quarterly, 2, 1-25.

Dickinson, D. K., \& Tabors, P. O. (Eds.). (2001). Beginning language with literacy: Young children learning at home and school. Baltimore, MD: Paul H. Brookes.

Dodd, B., \& Conn, L. (2000). The effect of braille orthography on blind children's phonological awareness. Journal of Research in Reading, 23, 1-11.

Foorman, B. R., \& Torgesen, J. (2001). Critical elements of classroom and small-group instruction promote reading success in all children. Learning Disabilities Research \& Practice, 16, 203-213.

Fraiberg, S. (1977). Insights from the blind. London: Souvenir Press. 
Geary, D. C. (1995). Reflections of evolution and culture in children's cognition. American Psychologist, 50, 24-37.

Gillon, G. T., \& Young, A. A. (2002). The phonological-awareness skills of children who are blind. Journal of Visual Impairment and Blindness, 97, 38-49.

Hatton, D. D., \& Erickson, K. (2006). The phonological, alphabetic, and print awareness of young children with visual impairments. Unpublished manuscript, University of North Carolina at Chapel Hill.

Hatton, D. D., \& Sapp, W. K. (2005). Interventions to facilitate emergent literacy. In W. K. Sapp \& D. D. Hatton, Communication and emergent literacy: Early intervention issues [multimedia compact disc]. Chapel Hill, NC: Frank Porter Graham Child Development Institute, University of North Carolina at Chapel Hill.

Herriman, M. (1991). Metalinguistic development. Australian Journal of Reading, 14, 326-338.

Holdaway, D. (1979). The foundations of literacy. New York: Ashton Scholastic.

Jordan, G. E., Snow, C. E., \& Porche, M. (2000). Project EASE: The effect of a family literacy project on kindergarten students' early literacy skills. Reading Research Quarterly, 35, 524-546.

Kekelis, L. S., \& Andersen, E. S. (1984). Family communication styles and language development. Journal of Visual Impairment \& Blindness, 78, 54-65.

Koenig, A. J., \& Farrenkopf, C. (1997). Essential experiences to undergird the early development of literacy. Journal of Visual Impairment \& Blindness, 91, 14-24.

Lamb, G. (1996). Beginning braille: A whole language-based strategy. Journal of Visual Impairment \& Blindness, 90, 184-189.

Legge, G. E., Madison, C., \& Mansfield, J. S. (1999). Measuring braille reading speed with the MNREAD test. Visual Impairment Research, 1, 131-145.

Lonigan, C. J., Burgess, S. R., \& Anthony, J. L. (2000). Development of emergent literacy and early reading skills in preschool children: Evidence from a latent-variable longitudinal study. Developmental Psychology, 36, 596-613.

Mason, J. M., \& Stewart, J. P. (1990). Emergent literacy assessment for instructional use in kindergarten. In L. M. Morrow \& J. K. Smith (Eds.), Assessment for instruction in early literacy (pp. 155-175). Englewood Cliffs, NJ: Prentice Hall.

McComiskey, A. V. (1996). The braille readiness skills grid: A guide to building a foundation for literacy. Journal of Visual Impairment \& Blindness, 90, 190-193.

McConachie, H. R. (1990). Early language development and severe visual impairment. Child: Care, Health, and Development, 16, 55-61.

McConachie, H. R., \& Moore, V. (1994). Early expressive language of severely visually impaired children. Developmental Medicine and Child Neurology, 36, 230-240.

National Reading Panel. (1998). Report of the National Reading Panel: Teaching children to read. Retrieved August 26, 2004, from http://www.nationalreadingpanel.org/ Publications/publications.htm

NICHD Early Child Care Research Network. (2005). Pathways to reading: The role of oral language in the transition to reading. Developmental Psychology, 41, 428-442.

Preisler, G. M. (1995). The development of communication in blind and in deaf infantsSimilarities and differences. Child: Care, Health, and Development, 21, 79-110.

Rex, E. J., Koenig, A. J., Wormsley, D. P., \& Baker, R. L. (1995). Foundations of braille literacy. New York: AFB Press.

Rogers, S., \& Puchalski, C. B. (1984). Social characteristics of visually impaired infants' play. Topics in Early Childhood Special Education, 3, 57-63.

Sapp, W. K. (2001). Maternal perceptions of preverbal communication in children with visual impairments. RE:view, 33, 133-144.

Sapp, W. K., \& Hatton, D. D. (2005a). Communication and emergent literacy: Early intervention issues [set of five multimedia compact discs]. Chapel Hill, NC: Frank Porter Graham Child Development Institute, University of North Carolina at Chapel Hill. 
Sapp, W. K., \& Hatton, D. D. (2005b). Communication development and the impact of visual impairments. In W. K. Sapp \& D. D. Hatton, Communication and emergent literacy: Early intervention issues [multimedia compact disc]. Chapel Hill, NC: Frank Porter Graham Child Development Institute, University of North Carolina at Chapel Hill.

Sapp, W. K., Murphy, J. L., \& Hatton, D. D. (2005). Communication and language interventions. In W. K. Sapp \& D. D. Hatton, Communication and emergent literacy: Early intervention issues [multimedia compact disc]. Chapel Hill, NC: Frank Porter Graham Child Development Institute, University of North Carolina at Chapel Hill.

Scarborough, H. (1998). Early identification of children at risk for reading disabilities: Phonological awareness and some other promising predictors. In B. K. Shapiro, P. J. Accardo, \& A. J. Capute (Eds.), Specific reading disability: A view of the spectrum (pp. 75-119). Timonium, MD: York Press.

Scarborough, H. (2001). Connecting early language and literacy to later reading (dis) abilities: Evidence, theory, and practice. In S. B. Neuman \& D. K. Dickinson (Eds.), Handbook of early literacy research (pp. 97-110). New York: Guilford Press.

Schatschneider, C., Fletcher, J., Francis, D., Carlson, C., \& Foorman, B. (2004). Kindergarten prediction of reading skills: A longitudinal comparative analysis. Journal of Educational Psychology, 96, 265-282.

Sénéchal, M., \& LeFevre, J. (2002). Parental involvement in the development of children's reading skill: A five-year longitudinal study. Child Development, 73, 445460.

Sénéchal, M., LeFevre, J., Smith-Chant, B. L., \& Colton, K. V. (2001). On refining theoretical models of emergent literacy: The role of empirical evidence. Journal of School Psychology, 39, 439-460.

Snow, C. E. (1983). Literacy and language: Relationships during the preschool years. Harvard Educational Review, 53, 165-189.
Speece, D. L., Roth, F. P., Cooper, D. H., \& de la Paz, S. (1997). The relevance of oral language skills to early literacy: A multivariate analysis. Applied Psycholinguistics, 20, 167-190.

Stratton, J. M. (1996). Emergent literacy: A new perspective. Journal of Visual Impairment \& Blindness, 90, 177-183.

Stratton, J. M., \& Wright, S. (1991). On the way to literacy: Early experiences for young visually impaired children. RE:view, $23,55-63$.

Sulzby, E., Branz, C. M., \& Buhle, R. (1993). Repeated readings of literature and low socio-economic status black kindergarteners and first graders. Reading and Writing Quarterly, 9, 183-196.

Swenson, A. (1999). Beginning with braille: Firsthand experiences with a balanced approach to literacy. New York: American Foundation for the Blind.

Tabors, P. O., Roach, K. A., \& Snow, C. E. (2001). Home language and literacy environment: Final results. In D. K. Dickinson \& P. O. Tabors (Eds.), Beginning literacy with language (pp. 111-138). Baltimore, MD: Paul H. Brookes.

Teale, W., \& Sulzby, E. (1986). Emergent literacy as a perspective for examining how young children become readers and writers. In W. H. Teale \& E. Sulzby (Eds.), Emergent literacy: Writing and reading (pp. vii-xxv). Norwood, NJ: Ablex.

Urwin, C. (1984). Communication in infancy and the emergence of language in blind children. In R. L. Schiefelbusch \& J. Pickar (Eds.), The acquisition of communicative competence (pp. 479-524). Baltimore, MD: University Park Press.

Vellutino, F. R., \& Scanlon, D. M. (2001). Emergent literacy skills, early instruction, and individual differences as determinants of difficulties in learning to read. In S. B. Neuman \& D. K. Dickinson (Eds.), Handbook of early literacy research (pp. 295321). New York: Guilford Press.

Wagner, R. K., Torgeson, J. K., Rashotte, C. A., Hecht, S. A., Barker, T. A., Burgess, S., Donahue, J., \& Garon, T. (1997). Changing relations between phonological processing 
abilities and word-level reading as children develop from beginning to skilled readers: A 5-year longitudinal study. Developmental Psychology, 33, 468-479.

Warren, D. H., \& Hatton, D. D. (2003). Cognitive development of children with visual impairments. In I. Rapin \& S. Segalowitz (Vol. Eds.), Handbook of neuropsychology. Volume 8, Part II: Child neuropsychology (2nd ed., pp. 439-458). New York: Elsevier.

Whitehurst, G. J., Epstein, J. N., Angell, A. L., Payne, A. C., Crone, D. A., \& Fischel, J. E. (1994). Outcomes of an emergent literacy intervention in Head Start. Journal of Educational Psychology, 86, 542-555.

Whitehurst, G. J., \& Lonigan, C. J. (1998). Child development and emergent literacy. Child Development, 69, 848-872.
Wormsley, D. P. (1997). Fostering emergent literacy. In D. P. Wormsley \& F. M. D'Andrea (Eds.), Instructional strategies for braille literacy (pp. 17-55). New York: American Foundation for the Blind.

Wormsley, D., \& D' Andrea, F. (Eds.). (1997). Instructional strategies for braille literacy. New York: American Foundation for the Blind.

Karen A. Erickson, Ph.D., director, Center for Literacy and Disability Studies, University of North Carolina, Campus Box 7335, Chapel Hill, NC 27599-7335; e-mail: <kae@med.unc.edu>. Deborah Hatton, Ph.D., senior scientist, Frank Porter Graham Child Development Institute, University of North Carolina, Campus Box 8040, Chapel Hill, NC 27599-8040; e-mail: < deborah_ hatton@unc.edu>. 